\title{
ANALYSIS OF POLICY AND ENVIRONMENTAL MANAGEMENT IN THE CITY OF ITAPIPOCA, CEARÁ
}

\author{
Francisco Xirlean Xavier Alves ${ }^{1}$ \\ Ivan Jeferson Sampaio Diogo ${ }^{2}$
}

\begin{abstract}
The Environmental Policy is a set of activities and procedures aimed at the management of the environment and coordinated by the different levels of competence and supranational organizations, of the State and nongovernmental companies and organizations, which intend to reach the final goal of protecting the environment. and nature conservation. Brazilian municipalities face a series of problems in relation to environmental
\end{abstract} management. The objective of this research was to analyze the environmental policy in the municipality of Itapipoca-CE based on its environmental licensing and activities, and inspection actions. A qualitative, descriptive case study was carried out, establishing a relationship between the factors addressed in this work and those of a bibliographic nature. The municipality of Itapipoca has great potential for diverse economic activities. Comparing the data of the records drawn

up over the years 2017, 2018 and until July 2019, there is an increase in complaints, inspections and environmental assessments. In addition, different Environmental Education strategies were observed in the application of projects and actions at the municipal level. The assessment of the management and environmental policy of the municipality of Itapipoca-CE showed the clear process of decentralization, where municipalities are organizing themselves and taking action in relation to their environmental issues, where licensing and inspection activities are increasingly being carried out.

Keywords: environmental education, environmental conservation, environmental licenses, notification notices.

\section{Introdução}

\footnotetext{
1 alvesxavier11@gmail.com. Faculdade Terra Nordeste - FATENE

2 ivan.diogo@ifpb.edu.br. Instituto Federal da Paraíba - IFPB, Campus Princesa Isabel
} 
No Brasil desde a primeira metade do século XX, a temática política ambiental vem trazendo à tona muitas discussões e contradições. Durante todo esse processo, tem-se observado cada vez mais a inserção das políticas ambientais nos órgão públicos e privados como uma estratégia de gestão ambiental federal, estadual e municipal. Philippi Jr. e Malheiros (2007) conceituam gestão ambiental municipal como "o processo político-administrativo que compete ao poder público local (Executivo e Legislativo) implementar, formular e avaliar políticas ambientais, com a participação da sociedade, visando assegurar qualidade ambiental e qualidade de vida aos cidadãos”.

A temática da centralização versus descentralização da política ambiental brasileira vem sendo discutida bastante na contemporaneidade, resultado de um processo de desenvolvimento crítico-político da sociedade brasileira. Tal desenvolvimento culminou na atual Constituição Federal de 1988, que trouxe avanços sobre o meio ambiente, porém com grandes desafios de implementação.

Para Teixeira e Santana (1995), a descentralização impõe-se como uma estratégia de primeira importância para fortalecer a delegação de competências aos diversos níveis da administração, apoiar órgãos com poderes descentralizados e, consequentemente, reverter à tendência altamente centralizadora do modelo de gestão vigente.

É preciso, antes de tudo, entender que em um sistema de gestão ambiental devem estar incluídas atividades de planejamento, o uso de práticas e métodos que visam reduzir ao máximo o impacto ambiental das atividades na natureza, além de responsabilidades, processos e recursos para desenvolver, implementar, atingir, analisar criticamente e manter a política ambiental, dando ênfase na sustentabilidade.

A Política Ambiental é um conjunto de atividades e procedimentos voltados para a gestão do meio ambiente e coordenada pelos diferentes níveis de competências e organizações, supranacionais, do Estado e as empresas e organizações não governamentais, que pretendem alcançar a meta final de proteção ao meio ambiente e conservação da natureza (FERNANDEZ-VÍTORA， 1997; SCARDUA, 2003). 
Dessa forma, o sistema

ambiental municipal brasileiro passa a atuar como responsável por atividades de gestão ambiental. Como frutos dessa conquista, os municípios passam a ter as suas próprias Políticas de Gestão Ambiental, bem como instrumentos como órgãos ambientais municipais, conselhos municipais de meio ambiente e legislação ambientais próprias. Como produto de tudo isso o município passa a realizar o licenciamento ambiental, fiscalização ambiental e atividades de educação ambiental, tornando-se mais efetivo e decisivo nas questões ambientais.

Em meio a crítica ambiental brasileira, esse trabalho busca avaliar a política ambiental no município de Itapipoca-CE, bem como analisar a execução de projetos, fiscalização e licenciamento, e descrever as ações em prol do desenvolvimento sustentável no referido município.

\section{Material e Métodos}

Figura 2 - Localização do município de Itapipoca no estado do Ceará, Brasil
Para atingir o objetivo proposto neste trabalho, realizou-se um estudo de caso com abordagem qualitativa, de caráter descritivo estabelecendo uma relação entre os fatores abordados nesse trabalho e os de cunho bibliográfico. Segundo Gil (2010), o estudo de caso é caracterizado pelo estudo profundo e exaustivo de um ou de poucos objetos, de maneira que permita o seu amplo detalhamento. $\mathrm{O}$ estudo de caso tem como vantagem a ênfase na interpretação em contexto, voltado para a multiplicidade de dimensões de um determinado problema, focalizando-o como um todo.

A pesquisa tem como foco a avaliação da política ambiental e desenvolvimento sustentável no município de Itapipoca-CE (Figura 2). Itapipoca é conhecida como "cidade dos três climas", por haver em seu território praias, serras e o sertão. O município é dividido em doze distritos. 


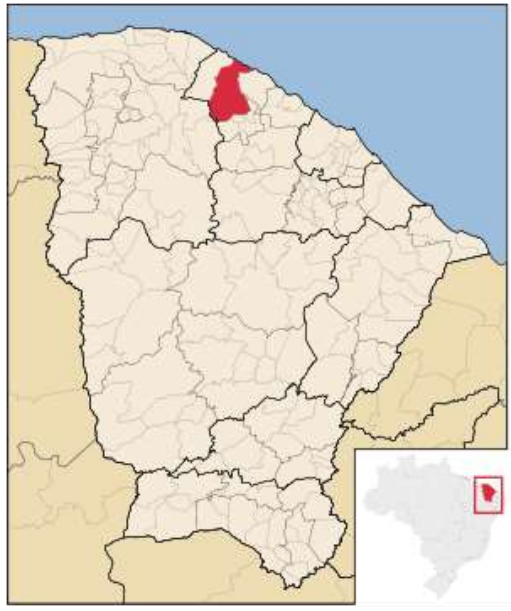

Fonte: Adaptado de IBGE (2010).

A vegetação predominante do território é a caatinga arbustiva e arbórea, tabuleiros costeiros e cerrado. Apresenta também áreas de mata úmida na região serrana e mangue próximo à foz do rio Mundaú. No Sítio Ameixas Poço Velho, localiza-se a primeira e única Unidade de Conservação Ambiental, uma Reserva Particular do Patrimônio Natural, com uma área de 464,3 hectares, criada pela portaria $\mathrm{N}^{\mathrm{o}}$ 007/94 do IBAMA em 28 de janeiro de 1994.

Nesse trabalho, foram analisados os dados em relação às ações desenvolvidas no Instituto de Meio Ambiente do Município de Itapipoca (IMMI), nos anos de 2017 a meados do ano de 2019, com o intuito de observar as atividades em ascensão e as principais dificuldades no desenvolvimento prático e efetivo das ações realizadas pelo IMMI. Dessa forma, foram selecionados diretrizes e ações coordenadas pelo Governo local, incluindo os projetos, planos, programas e estratégias de gestão que enfoquem a política ambiental através do acesso aos documentos, leis e relatórios municipais.

\section{Resultados e Discussão}

$\mathrm{O}$ órgão fiscalizador $\mathrm{e}$ licenciador do município trata-se de uma autarquia denominada de Instituto de Meio Ambiente do Município de Itapipoca (IMMI). Além das atividades descritas, o órgão municipal atua na área de educação ambiental e reflorestamento do município, desde vias dentro do perímetro urbano até os distritos que compõem o município. 
O IMMI, como órgão fiscalizador ambiental, em parceria com os demais órgãos, Estado e União, exerce fiscalização sobre o meio ambiente de forma em geral. Portanto, todos os empreendimentos implantados no município dependem de licenças ambientais, carta de anuência e autorizações ambientais, todos emitidos pelo órgão ambiental do município.

O município de Itapipoca é referência na região Oeste pelo empenho e cuidado com o meio ambiente, recebendo premiações pelos serviços realizados em todo o município, como a Certificação Praia Limpa e o destaque nacional em gestão ambiental municipal pela Associação Nacional dos Órgãos Municipais de Meio Ambiente ANAMMA.

Mesmo destacando-se no cenário ambiental estadual e nacional, o município enfrenta problemas relacionados à fiscalização e licenciamento. A política municipal de meio ambiente ainda não é difundida de maneira que alcance todos os munícipes, dificultando assim a fiscalização ambiental e o licenciamento ambiental.

Esses fatores englobam desde problemas estruturais, burocráticos e até financeiros, como a falta de técnicos nos órgãos estaduais e municipais de meio ambiente; a falta de capacitação e treinamento; os salários defasados, quando comparados aos praticados pela iniciativa privada; as instituições despreparadas para assumir atividades ambientais; a carência de recursos financeiros e de infraestrutura; a ausência de instrumentos de gestão ambiental ou instrumentos ultrapassados (SOUZA et al., 2003).

\section{Fiscalização ambiental}

As fiscalizações permanentemente do uso dos recursos ambientais, em geral, são indispensáveis na busca da efetivação da política ambiental e desenvolvimento sustentável do município. Elas são efetivadas quando a população realiza denúncias, seja via presencial no próprio IMMI, pelo telefone, e-mail e redes sociais, ou quando a infração ambiental é visível e identificada pelos fiscais de meio ambiente do IMMI.

Nessas fiscalizações, os fiscais de meio ambiente podem lavrar os seguintes autos: auto de notificação, auto de infração e suspensão da atividade por meio da aplicação de embargo. Quando autuado, o infrator é convocado para 
comparecer ao IMMI a fim de assinar um Termo de Compromisso e Ajustamento de Conduta (TCAC) e fornecer a documentação necessária para sua devida regularização.

As ações de fiscalização no município de Itapipoca-CE, são regidas pelas seguintes leis: Lei da Política Nacional de Meio Ambiente $\mathrm{N}^{\circ}$ 6.938/1981; Lei de Crimes Ambientais No 9.605/1998; Lei da Política Nacional dos Resíduos Sólidos N 12.305/2010; Código Florestal Brasileiro Lei $\mathrm{N}^{\circ}$ 12.651/2012, Decreto No 6.514/2008 que discorre sobre as infrações e sanções administrativas ao meio ambiente, estabelece $\mathrm{o}$ processo administrativo federal para apuração destas infrações.

Devido ao seu porte e desenvolvimento acelerado, o município de Itapipoca apresenta um grande potencial para atividades comerciais, agriculturais, de pecuária e industriais, consequentemente uma diversidade de fontes geradoras de impactos ao meio ambiente (Tabela 3). Com base nisso, a fiscalização ambiental do município, fica sempre alerta a essas atividades poluidoras, bem como seus impactos, afim de sanar ou minimizar o dano ao meio ambiente e responsabilizar o responsável.

Tabela 3 - Atividades causadoras de Impactos Ambientais no Município de ItapipocaCE

\begin{tabular}{|c|c|c|}
\hline Atividades & Impactos & Responsáveis \\
\hline $\begin{array}{l}\text { Disposição de materiais } \\
\text { diretamente no solo e na água }\end{array}$ & Poluição hídrica e edáfica & $\begin{array}{l}\text { Serrarias e obras de } \\
\text { construção civil }\end{array}$ \\
\hline $\begin{array}{l}\text { Criação de animais nos perímetros } \\
\text { urbanos }\end{array}$ & $\begin{array}{l}\text { Acidentes, poluição do } \\
\text { solo, odor desagradável }\end{array}$ & $\begin{array}{l}\text { Pequenos agricultores, } \\
\text { açougueiros }\end{array}$ \\
\hline Ausência de saneamento básico & $\begin{array}{l}\text { Vetores de doenças; } \\
\text { mau cheiro }\end{array}$ & Setor público \\
\hline $\begin{array}{l}\text { Utilização de equipamentos } \\
\text { sonoros ultrapassando os limites } \\
\text { admitidos pela lei }\end{array}$ & Poluição sonora & $\begin{array}{l}\text { Proprietários de } \\
\text { paredões, clubes, } \\
\text { casas de shows e bares }\end{array}$ \\
\hline Mineração & Poluição hídrica e edáfica & $\begin{array}{l}\text { Construção civil, } \\
\text { pessoas que } \\
\text { sobrevivem da venda } \\
\text { de areia, quebra de } \\
\text { rocha }\end{array}$ \\
\hline
\end{tabular}


Esgotos dispostos diretamente no solo e corpos hídricos

\section{Indústrias}

Animais silvestres em cativeiros

Movimentação de terra

Desmatamento
Vetores de doenças, mau cheiro
Esgotos clandestinos, residências, criação de animais

Alto consumo de recursos naturais, bem como água e energia, Poluição atmosférica

Morte dos animais, estresse dos animais, venda dos mesmos

Erosões, barragens clandestinas

Erosões, queimadas, descoberta do solo, retirada da flora nativa e extinção da fauna silvestre
Fábrica de calçados, indústria de derivados do coco

Criadores irregulares
Proprietários de máquinas pesadas

Agricultores, Loteamentos

FONTE: O Autor

De acordo com a Política Municipal de Meio Ambiente de Itapipoca-CE (2009), as atividades e empreendimentos potencialmente causadores de impactos ambientais dependerão de licença ambiental municipal sem prejuízo de outras licenças exigíveis.

Comparando-se os dados dos autos lavrados ao longo dos anos 2017, 2018 e até julho de 2019, percebe-se um crescimento nos autos de notificação, isso deve-se a fiscalização efetiva nos em todo território do município (Figura 1). Em relação aos autos de infração percebemos uma diminuição no ano de 2018 quando comparamos a 2017 e 2019, mesmo sabendo que o ano de 2019 ainda estar em curso (Figura 1), isso se dá por conta da capacitação maior dos fiscais, onde entende-se que deve seguir uma ordem na lavragem dos autos, somente deve ser utilizado diretamente o auto de infração quando o dano é grande ou quando descumpre-se outro auto seja notificação, ou TCAC.

A quantidade de denúncias deu uma subida no ano de 2018 em relação a 2017 e uma decaída até julho de 2019 (Figura 1), vale ressaltar que a 
queda se deve à constante fiscalização nas ruas e comunidades que compõem o município. A aplicação de embargos partira de 0 (zero) no ano de 2017 para uma subida no ano de 2028 a 2019, fato que se deu devido a formação intensa dos fiscais de meio ambiente do município.

Os termos de ajustamento de compromisso - TCAC, apresentam um crescimento nítido nos aos de 2018 e 2019 e, relação a 2017. Isso se deve a fiscalização efetiva, aumentando os autos de notificações e infrações lavrados, bem como a eficiência no atendimento a demanda de denúncias da população itapipoquense.

Figura 1 - Comparativo de ações decorrente da fiscalização no município de ItapipocaCE durante os anos de 2017, 2018, e meados de 2019. AN = Auto de Notificação, AI = Auto de Infração, $\mathrm{D}=$ Denúncias, $\mathrm{E}=$ Embargos e, $\mathrm{T}=$ Termo de Ajustamento de Conduta (TCAC).

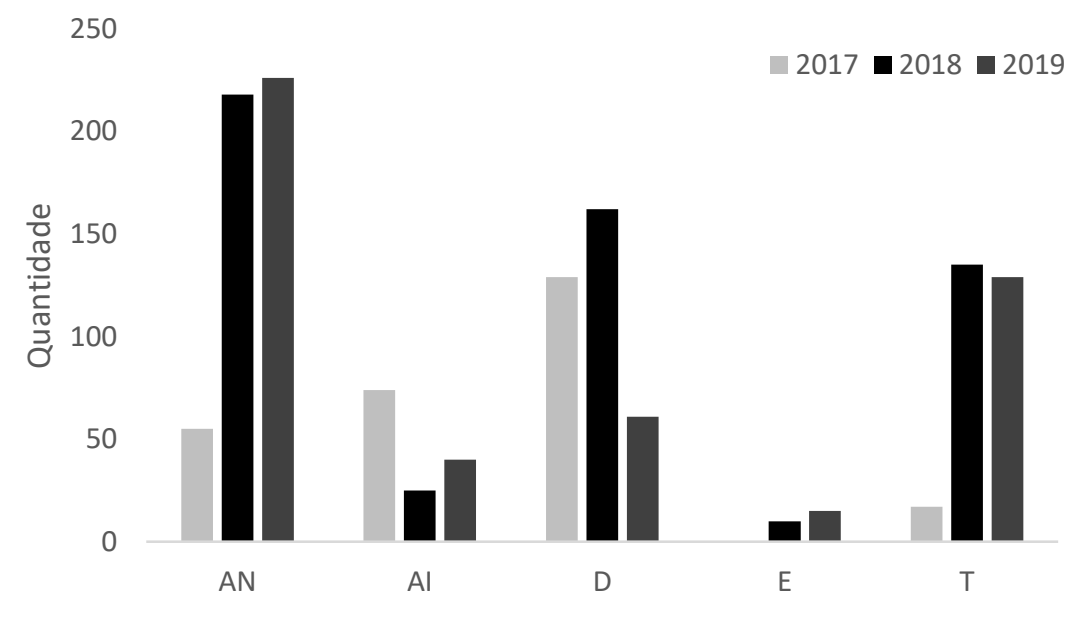

Fonte: O Autor

Scardua e Bursztyn (2003)

afirmam que a baixa presença de municípios que contam com algum órgão para tratar de meio ambiente $(11,7 \%)$, aliada ao baixo número de Conselhos Municipais de Meio
Ambiente (21,37\%) são indicativos de que o meio ambiente ainda não é prioridade, ou ainda não representa um problema para os municípios brasileiros.

\section{Licenciamento ambiental}


De acordo com a Política Ambiental Municipal, o IMMI pode emitir diversas autorizações de licenciamento para atividades econômicas potencialmente poluidoras, são elas: Carta de Anuência (Uso e ocupação do solo), Autorização ou Licença Ambiental, podendo ser Licença
Prévia (LP), Licença de Instalação (LI) e Licença de Operação (LO). Para cada licença ou autorização solicitada, é realizada uma vistoria pelos técnicos de licenciamento, no local do empreendimento, com devido cuidado de profissionais capacitados na área de gestão ambiental.

Figura 2 - Quantidade de atividades de licenciamento no município de Itapipoca-CE, durante os anos de 2017 e 2018. AA= Autorização Ambiental, CA= Carta de Anuência, LO= Licença de Operação, LP= Licença Prévia, LI= Licença de Instalação, LO= Licença de Operação, LS= Licença Simples, LSO= Licença Sonora, MT = Mudança de Titularidade

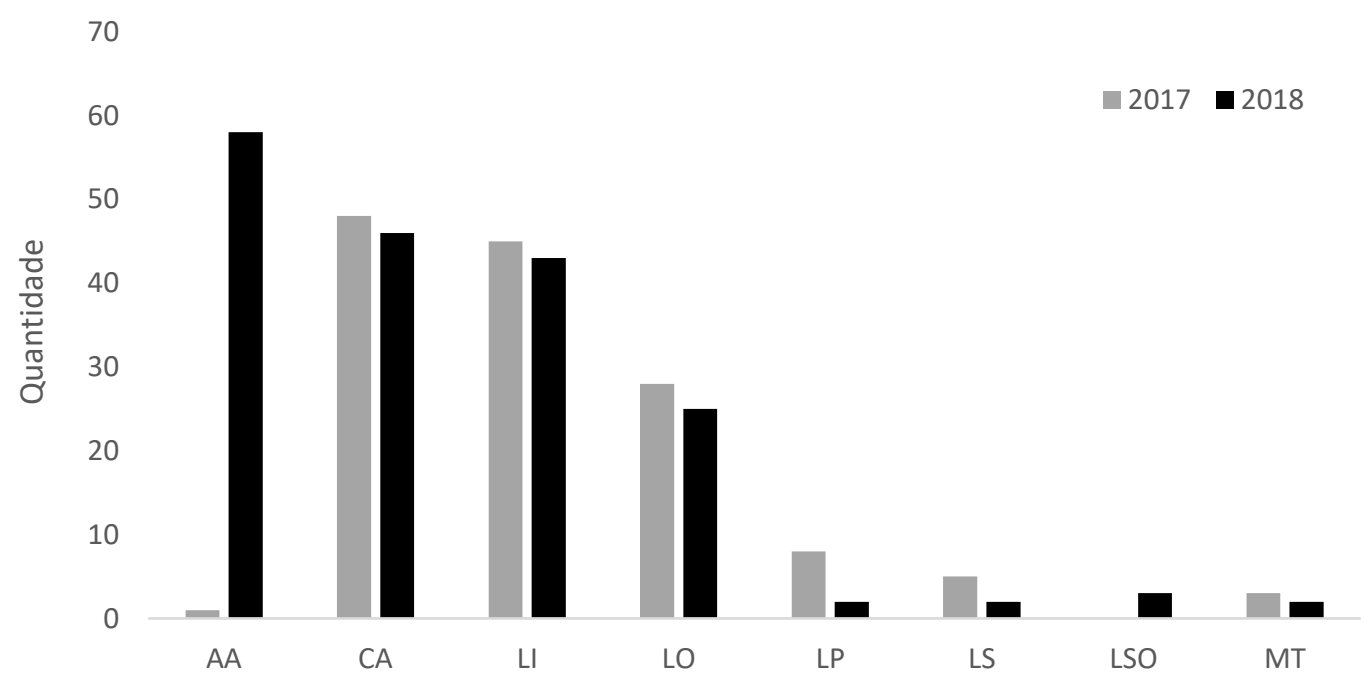

Fonte: O Autor

Com base na figura 2, é nítido que houve um grande aumento de autorizações ambientais concedidas entre os anos de 2017 e 2018, ocorrendo principalmente devido a fatores como pedidos da população para corte e/ou retirada de árvores, bem como a autorização para utilização de som no município. 
Percebe-se também que as cartas de anuência emitidas permaneceram em quantidades parecidas, dando um leve declínio no ano de 2018, algo que se assemelha a quantidade de licenças emitidas, sendo que no ano de 2017 em relação a 2018, as licenças permaneceram com uma pequena diferença, respectivamente, Licença prévia, Licença de Instalação, Licença de Operação, sendo que a quantidade de licença de instalação emitidas superou as outras licenças citadas anteriormente.
As licenças simples apresentaram uma queda no ano de 2018 em relação a 2017, diferente das licenças sonoras que apresentaram um crescimento acentuado. A mudança de titularidade permaneceu instável com uma pequena queda no ano 2018 em relação ao ano de 2017.

De acordo com Mendonça (2019), foram lavrados 1.533 autos de infração, tendo a SEMACE atuado em todos os 19 municípios da Região Metropolitana de Fortaleza - RMF ao longo do período de 2014 a 2018.

Figura 3 - Regularizações de licenças dos anos de 2017 e 2018. LI = Licença de Instalação, LO = Licença de Operação

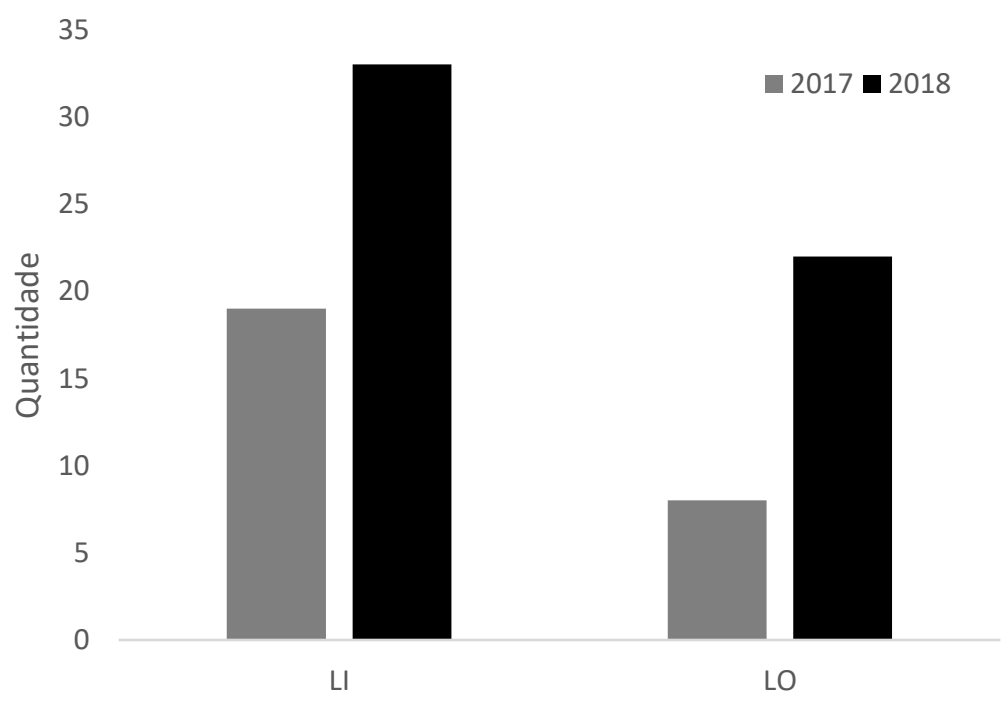

Fonte: O Autor 
Ao comparar as licenças de Instalação, pode-se perceber que houve um aumento significativo em 2018 com relação a 2017. O mesmo ocorreu com as licenças de Operação no mesmo período.
Isso se deve principalmente, a fiscalização efetiva nas construções e empreendimentos sem licença ambiental do município de Itapipoca.

Figura 6 - Renovações de Licenças ambientais nos anos de 2017 a 2018. CA = Carta de Anuência, LI = Licença de Instalação, LO = Licença de Operação, LP = Licença Prévia

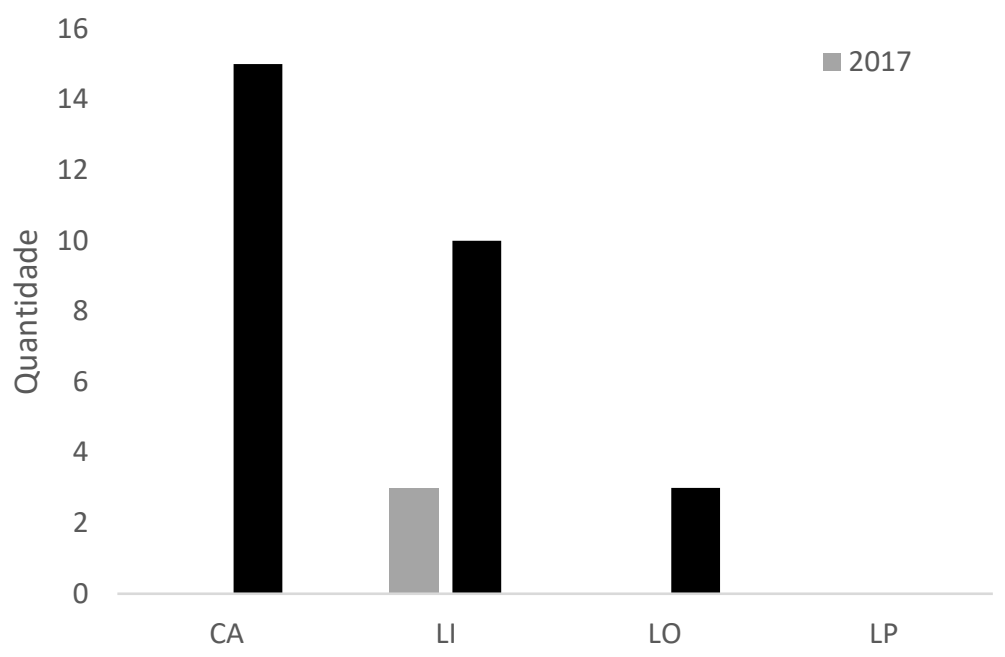

Fonte: O Autor

O IMMI, sendo o órgão ambiental competente estabelece os prazos de validade de cada tipo de licença, prazos esses que esgotados necessitam de renovações. Se observarmos houve um crescimento na renovação de todas as licenças mostradas na Figura 5. Se compararmos 2018 em relação a 2017 a renovação de cartas de anuência cresceu de 0 a 15 , a licença de Instalação de 3 a 10 e a licença de operação de 0 a 3, deixando nítido um crescimento ao longo dos dois anos.

Os valores dos custos operacionais a serem pagos pelo empreendedor serão, de acordo com o decreto municipal 068/2009, fixados em função do porte e do potencial poluidor degradador (PPD) do empreendimento ou atividade, sendo gerado o recibo para o interessado efetuar o pagamento. Após esse processo, é emitida a Carta de Anuência, Autorização Ambiental ou 
uma das três Licenças Ambientais: LP, LI ou LO.

\section{Educação ambiental}

A Educação Ambiental é realizada pelo IMMI por meio de palestras e oficinas nos mais diversos espaços públicos do município, visando sensibilizar a população itapipoquense sobre o uso racional da água, da coleta seletiva e da reciclagem do lixo, da importância de se evitar o desmatamento e as queimadas; e implementar a ideia de sustentabilidade em qualquer atividade econômica-social do município.

Dentro das atividades de Educação Ambiental, uma série de palestras já realizadas podem ser citadas, por exemplo: palestra sobre destinação de resíduos sólidos na comunidade de Santa Rita, Arapari, Itapipoca-CE; palestra lixo é luxo; palestra na reunião do Conselho da APA do Rio Mundaú, abordando a importância das plantas, método de plantio, projeto de arborização de Itapipoca, benefícios da moringa, dimensões da sustentabilidade, princípio do in dubio pro natura; palestra na fábrica Dass, abordando a importância da árvore para sociedade itapipoquense; palestra no distrito de Deserto na Escola de Ensino Médio
Hildeberto Barroso, abordando o tema queimadas - concepção acerca da queimadas do município de Itapipoca$\mathrm{CE}$, dentre outras.

São realizadas também oficinas, como as de produção de sabão ecológico nas comunidades do município, visando à sensibilização e a conscientização do descarte adequado do óleo residual, proporcionando o conhecimento teórico e prático a respeito da produção de sabão em barra e em líquido. Dessa forma, essas atividades priorizam o consumo economicamente sustentável e a possibilidade de geração de renda para a população local.

Muitas outras ações de educação ambiental estão atreladas a grandes eventos e datas comemorativas, sejam eles/elas federais, Estaduais ou Municipais, por exemplo, podemos citar o dia do Pau Brasil, a Festa Anual das Árvores, a Semana do Meio Ambiente e a Exposição Agropecuária em conjunto com a semana de comemoração de aniversário do município de ItapipocaCE.

Diante disso pode-se afirmar ainda que a educação ambiental deve estar atrelada aos mais diversos setores do desenvolvimento econômico, principalmente naquele que visa a 
preservação ambiental de forma clara, com o intuito de cuidar para as próximas gerações: $\quad$ o desenvolvimento sustentável. A educação ambiental deve construir uma cultura ecológica que compreenda natureza e sociedade como variáveis inter-relacionadas e que não podem ser pensadas separadamente em decisões governamentais ou nas ações da sociedade civil (SORRENTINO, 2005).

Por ter ganhado muita visibilidade no século $\mathrm{XX}$ e, ser considerado de extrema necessidade para o desenvolvimento no cenário atual, o desenvolvimento sustentável torna-se uma tendência efetiva pois busca um equilíbrio entre o crescimento econômico e o cuidado com a natureza em suas múltiplas e diversas formas.

\section{Projetos}

A construção e realização de projetos são uns dos pontos fortes do IMMI. Por ser uma equipe multidisciplinar e formada por profissionais capacitados, os projetos realizados apresentam aceitação da população e qualidade no trabalho desenvolvido, dando respaldo para a construção de novos projetos. Alguns projetos de sucesso que já foram implantados ou estão em fase de implantação serão citados a seguir.

Com objetivo principal arborizar a sede do município de Itapipoca-CE, o Projeto de reflorestamento do município de Itapipoca-CE, visa melhorar a qualidade de vida da população por intermédio da diminuição da "ilha de calor", do "aumento do sequestro de gás carbônico", da "maximização da área naturalmente sombreada", da "beleza paisagística" e de outros benefícios vitais advindos das plantas. Exemplos de plantas utilizadas na arborização são: Ipê-amarelo, ipê-branco, ipê-roxo, ipêrosa, jacarandá, oiticica, entre outras. As respectivas plantas são dispostas nos canteiros centrais das avenidas, em frente a instituições do município e nos contornos das ruas e avenidas no interior do município.

O Projeto produção e doações de plantas ocorre por meio da troca de material reciclável por mudas, no caso, para cada 3 caixas de leite usadas que o/a cidadão/cidadã traz, é doada uma muda de planta (Tabela 4). Este projeto ocorre em conjunto com a população itapipoquense para a limpeza da cidade. $\mathrm{O}$ referido projeto também ocorre em parceria com as escolas da 
rede municipal de educação, captando as caixas de leite utilizadas na merenda escolar, para serem reaproveitadas na produção de mudas, servindo como porta-mudas.

Tabela 4. Espécies cultivadas no IMMI para arborização e distribuição no município de Itapipoca-CE

\begin{tabular}{ll}
\hline Nome popular & Nome científico \\
\hline Angico & Anadenanthera colubrina (Vellozo) Brenan \\
Aroeira & $\frac{\text { Myracrodruon Urundeuva Fr. All }}{\text { Poincianella pyramidalis (Tul.) }}$ \\
Catingueira & Anacardium occidentale L. \\
Cajueiro & Dalbergia nigra Vellozo \\
Jacarandá & Zizyphus joazeiro Mart. \\
Juá & Moringa oleífera Lam. \\
Moringa & Guazuma ulmifolia Lam. \\
Mutamba & Licania rígida Benth. \\
Oiticica & Cordia oncocalyx Allemão \\
Pau Branco & Handroanthus chrysotricha (Mart. ex DC) J. Mattos \\
Ipê Amarelo & Handroanthus roseo-alba (Ridl.) \\
Ipê Branco & Handoranthus pentaphylla Hemsl \\
Ipê Rosa & Handroanthus heptaphylla (Vell.) Tol. \\
Ipê Roxo & Mimosa caesalpiniifolia Benth. \\
Sabiá &
\end{tabular}

Fonte: O Autor

As mudas são posteriormente distribuídas às populações locais. Ambas ações contribuem para minimizar os efeitos adversos das mudanças de temperatura e precipitação, decorrentes de ações causadas pelo homem.
Outro projeto de destaque ao nível nacional e que está na fase final de construção é o Projeto de Gestão Integrada da Orla Marítima (Projeto Orla). Trata-se de uma ação conjunta entre o Ministério do Meio Ambiente, por intermédio de sua Secretaria de 
Extrativismo e Desenvolvimento Rural Sustentável (SEDR), e o Ministério do Planejamento, Orçamento e Gestão, no âmbito da sua Secretaria do Patrimônio da União (SPU/MP). Suas ações buscam o ordenamento dos espaços litorâneos sob domínio da União, aproximando as políticas ambiental e patrimonial, com ampla articulação entre as três esferas de governo e a sociedade, trazendo uma abordagem sustentável e participativa, promovendo ações de regularização fundiária nas áreas da União, através de celebração de convênio junto a Secretaria de Patrimônio da União - SPU (MMA).

As atividades do Projeto Orla em Itapipoca iniciaram com a adesão do município ao Projeto Orla Nacional e apresentação dos objetivos do projeto pela Comissão Técnica Estadual - CTE. Após isso, foram selecionados membros da equipe técnica municipal, que iniciaram os trabalhos de envolvimento dos diversos segmentos sociais locais. A capacitação de gestores se deu em duas etapas, onde foram realizadas oficinas, onde membros representantes da sociedade local expressam suas opiniões a respeito de como está a realidade da faixa praia naquele momento, pontos negativos e positivos, e sugerem benfeitorias que gostariam de ver naquela área.

O Projeto Sementes do Bioma Caatinga é advindo da Campanha da Fraternidade do ano de 2017, que teve como tema: Biomas Brasileiros e Defesa da Vida. O projeto se deu através de uma parceria interorganizacional entre a Caritas Diocesana de Itapipoca, o IMMI, a Rede de Intercâmbio de Sementes RIS e a Faculdade de Educação de Itapipoca - FACEDI para selecionar 40 comunidades e em seguida executar o projeto.

Esse Projeto teve por objetivo levar o conhecimento sobre o Bioma Caatinga, refletir sobre a importância da sua biodiversidade, promover e desenvolver ações comunitárias a fim de preservar o meio ambiente. Como resultado, elaborou-se um plano de ação para cada comunidade, contendo com três ações a serem desenvolvidas pelos membros dessas comunidades. As ações mais comuns foram: limpeza da comunidade e do rio, plantação de mudas para reflorestamento, construção de um banco de sementes com o objetivo de guardar a sementes para que não falte para o agricultor. 
Fernandes e Jerônimo (2013) discutem ser fundamental a elaboração de políticas municipais específicas ou planos de ação na área de Educação Ambientak e sua inserção nos projetos e atividades do município, fazendo com que a população possa trocar conhecimentos e experiências que possibilitem a conscientização e $\mathrm{o}$ pertencimento socioambiental. Os projetos acima descritos continuam sendo realizados pelo IMMI em parceria com os órgãos municipais da gestão e já beneficiaram a maioria da população do município. No ano de 2018, foram doadas 1500 mudas, com a finalidade primordial de preservação e conservação ambiental, propiciando assim o desenvolvimento sustentável e uma cidade mais agradável.

\section{Ações diversas}

Tem-se registrado as diversas mudanças de temperatura e precipitações pluviométricas no Município através da Estação Automática de Itapipoca como: Temperatura $\left({ }^{\circ} \mathrm{C}\right)$, Pressão (hPa), Vento $(\mathrm{m} / \mathrm{s})$, Radiação $\left(\mathrm{W} / \mathrm{m}^{2}\right)$ e Pluviometria (mm) (INMET, 2019). Dessa forma, o IMMI monitora diariamente as queimadas no perímetro do município, tendo como objetivo minimizar os danos causados pelo homem ao meio ambiente.

Outra ação, se dá no meio rural do município por meio do Cadastro Ambiental Rural (CAR), que é um instrumento fundamental para auxiliar no processo de regularização ambiental de propriedades e posses rurais. Este consiste no levantamento de informações georreferenciadas do imóvel, com delimitação das Áreas de Proteção Permanente (APP), Reserva Legal (RL), remanescentes de vegetação nativa, área rural consolidada, áreas de interesse social e de utilidade pública, com o objetivo de traçar um mapa digital a partir do qual são calculados os valores das áreas para diagnóstico ambiental.

Em 2017, o município de Itapipoca assinou junto à Secretaria de Patrimônio da União o Termo de Adesão à Gestão das Praias Marítimas Urbanas, o qual tem como finalidade transferir ao município a gestão destas praias, estabelecendo condições para uma melhor gestão dos espaços litorâneos, promovendo uma melhoria continuada, orientada para o uso racional e a qualificação ambiental e urbanística desses territórios.

Dentro dessas ações, o Conselho Municipal de Defesa do Meio 
Ambiente (COMDEMA) iniciou suas atividades no mês de fevereiro de 2016, dando uma pausa e reiniciou suas atividades novamente em maio de 2017. Desde seu início, foram realizadas 29 (vinte e nove) reuniões ordinárias, e 2 (duas) reuniões extra ordinárias, onde são discutidas e evidenciadas as ações que estão sendo desenvolvidas pelo IMMI no aspecto de desenvolvimento e defesa do meio ambiente.

O IMMI também realiza suas atividades na Farmácia Viva, local onde é cultivado espécies da flora que possuem cunho medicinal. O objetivo é que, posteriormente, seja montado um laboratório com condições que possam produzir medicamentos com base no conhecimento técnico dos profissionais que serão contratados, e levando em consideração o saber popular das famílias que existem na zona rural do município. Hoje, o IMMI apresenta no espaço da farmácia viva 80 canteiros produzindo ervas medicinais das mais variadas espécies, como mostrada na tabela a seguir.

Tabela 5 - Plantas cultivadas na Farmácia Viva do Instituto de Meio Ambiente de Itapipoca-CE

\begin{tabular}{ll}
\hline Nome Popular & Nome Científico \\
\hline Agrião & Acmella oleracea (L.) RK Jansen \\
Babosa & Aloe vera Linn. \\
Boldo & Peumus boldus Mol. \\
Corama preta & Kalanchoe pinnata (Lam.) Pers. \\
Camomila & Matricaria chamomilla L. \\
Colônia & Alpinia zerumbet (Pers.) BL Burtt \& RM Sm \\
Erva cidreira & Melissa officinalis L. \\
Hortelã vick & Mentha arvensis L. \\
Malva corama & Malva sylvestris L. \\
Malva santa & Plectranthus amboinicus (Lour.) Spreng. \\
Xambá & Justicia pectoralis Jacq. \\
\hline Fonte: O Autor
\end{tabular}

Fonte: O Autor 
As ervas medicinais produzidas na Farmácia Viva pelos viveristas, ficam à disposição da população itapipoquense, que sempre vão em busca das mesmas quando necessitam. Na maioria das vezes levam consigo resíduos com lâmpada queimadas, material proveniente de Pets, pilhas entre outros, ajudando a manter o município limpo e, evitando que esse material seja disposto diretamente no lixão.

Por fim, observa-se que a consolidação da participação da população, por meio dos conselhos consultivos e deliberativos, e o processo de capacitação feito pelas ações do IMMI proporcionam o engajamento da sociedade na construção da qualidade social, ambiental e econômica do município. Exercendo os objetivos do desenvolvimento sustentável, a população pode vir a atuar como agente multiplicador, contribuindo para a geração de ações contributivas de ética e cidadania.

\section{Considerações Finais}

Ao discutir o tema, procurou-se abordar a legislação ambiental brasileira em seus vários aspectos, níveis e caminhos percorrido até os dias atuais. A avaliação da política ambiental e desenvolvimento sustentável do município de Itapipoca-CE mostrou o processo claro de descentralização, onde municípios estão se organizando e tomando frente em relação às suas questões ambientais.

A condição geográfica do município de Itapipoca é um ponto a ser gerido de forma estratégica, dentro de contexto e enfoque regional. Ressalta-se que os municípios cearenses, bem como os brasileiros em geral, têm por obrigação aplicar a política ambiental, deixá-la fora do papel. Faz-se necessário sair da zona de conforto e enfrentar os desafios relacionados ao cuidado $\mathrm{e}$ proteção ao meio ambiente, demonstrando como a legislação ambiental oferece condições para que se cuide do meio ambiente, preservando-o e assim garantindo as mesmas ou melhores oportunidades para as gerações futuras.

Com a efetivação da Política Municipal de Meio Ambiente, o município de Itapipoca-CE passou a fortalecer sua atuação na proteção e preservação de suas riquezas naturais. Dessa forma, a gestão municipal passou a agir com ações de fiscalização, licenciamento dos empreendimentos potencialmente poluidores, 
desenvolvendo projetos que visam qualidade de vida, conscientizando a comunidade itapipoquense sobre a preservação de seus bens naturais, como uma maneira de garantir um local mais desenvolvido, porém agradável para as futuras gerações.

O conjunto de experiências que a pesquisa analisou apresenta um processo diferencial e inovativo dentro da gestão socioambiental municipal. As experiências bem sucedidas devem ser aproveitadas destacando-se que as realizações e dificuldades dos municípios representam espaço importante para a troca de experiências e avanços no campo da política e gestão ambiental.

\section{Referências}

FERNANDES, A.L.B.; JERÔNIMO, C.E.M. Análise da implementação da política municipal de Educação Ambiental no município de Natal-RN. Monografias Ambientais, v.11, n.11, p. 2410-2425, 2013.

FERNANDEZ-VÍTORA， V. C. Los instrumentos de la gestion ambiental en la empresa. Madrid: Ediciones Mundi-Prensa, p. 541,1997.
FORTALEZA. PMMA. Minuta da política Municipal de Meio Ambiente do Município de Fortaleza Ceará.

GIL, A. C. Como elaborar projetos de pesquisa. 5. ed. São Paulo: Atlas, 2010. ITAPIPOCA. PMMA (2009). Política Municipal de Meio Ambiente do Município de Itapipoca Ceará. Disponível em documento no IMMI.

ITAPIPOCA. 2008. Decreto Municipal 048/2008. Disponível em documento no IMMI.

ITAPIPOCA. 2009. Decreto Municipal 068/2009. Disponível em documento do IMMI.

MENDONÇA, P. S., DE OLIVEIRA, U. C., MAIA, A. M., ARAGÃO, T. B., ALBERTO, C., \& JÚNIOR, M. Análise da fiscalização ambiental estadual nos municípios da região metropolitana de fortaleza entre os anos de 2014 e 2018 . In: Anais do X Congresso Brasileiro de Gestão Ambiental Fortaleza/CE. 2019.

PHILIPPI Jr, A.; MALHEIROS, T. F. Gestão ambiental local. In: SANTANNA, P. Planejamento urbano e avaliação do impacte na saúde. Coimbra: Universidade de Coimbra. 2007.

SCARDUA, F. P. Governabilidade e descentralização da gestão ambiental 
no Brasil. Brasília. Tese (Doutorado) Centro de Desenvolvimento Sustentável da Universidade de Brasília. p. 234, 2003.

SORRENTINO, Marcos et al. Educação ambiental como política pública. Educ. Pesqui., São Paulo, v. 31, n. 2, p. 285299, Aug. 2005.

SOUZA, C. M. de. Democracia, participação social e funcionamento das instituições: situação e perspectivas da federalização do desenvolvimento. Revista de Administração Pública, Rio de Janeiro, v. 26, n. 3, p. 15-35, 1992.

SOUZA, E. C. B. et al. Desafios da gestão ambiental nos municípios. In: LITTLE, Paul(org). Políticas Ambientais no Brasil. Parte II: Políticas ambientais locais e Participativas. São Paulo, Peirópolis; Brasília, IIEB, 2003.

TEIXEIRA, H. J. SANTANA, S. M. Remodelando a gestão pública. São Paulo: Ed. Edgard Blücher Ltda: 1995 